\title{
Recombinant Inhibin
}

National Cancer Institute

\section{Source}

National Cancer Institute. Recombinant Inhibin. NCI Thesaurus. Code C578.

Recombinant therapeutic agents chemically identical to or similar to endogenous glycoproteins which inhibit pituitary production of follicle-stimulating hormone (FSH).

Inhibin has two isoforms: inhibin $\mathrm{A}$ and $\mathrm{B}$, both are dimmers of the same alpha subunit and different beta subunits. A member of the transforming growth factor beta superfamily, inhibins are secreted by the gonads and contribute to the control of gametogenesis, embryonic and fetal development and hematopoiesis. 